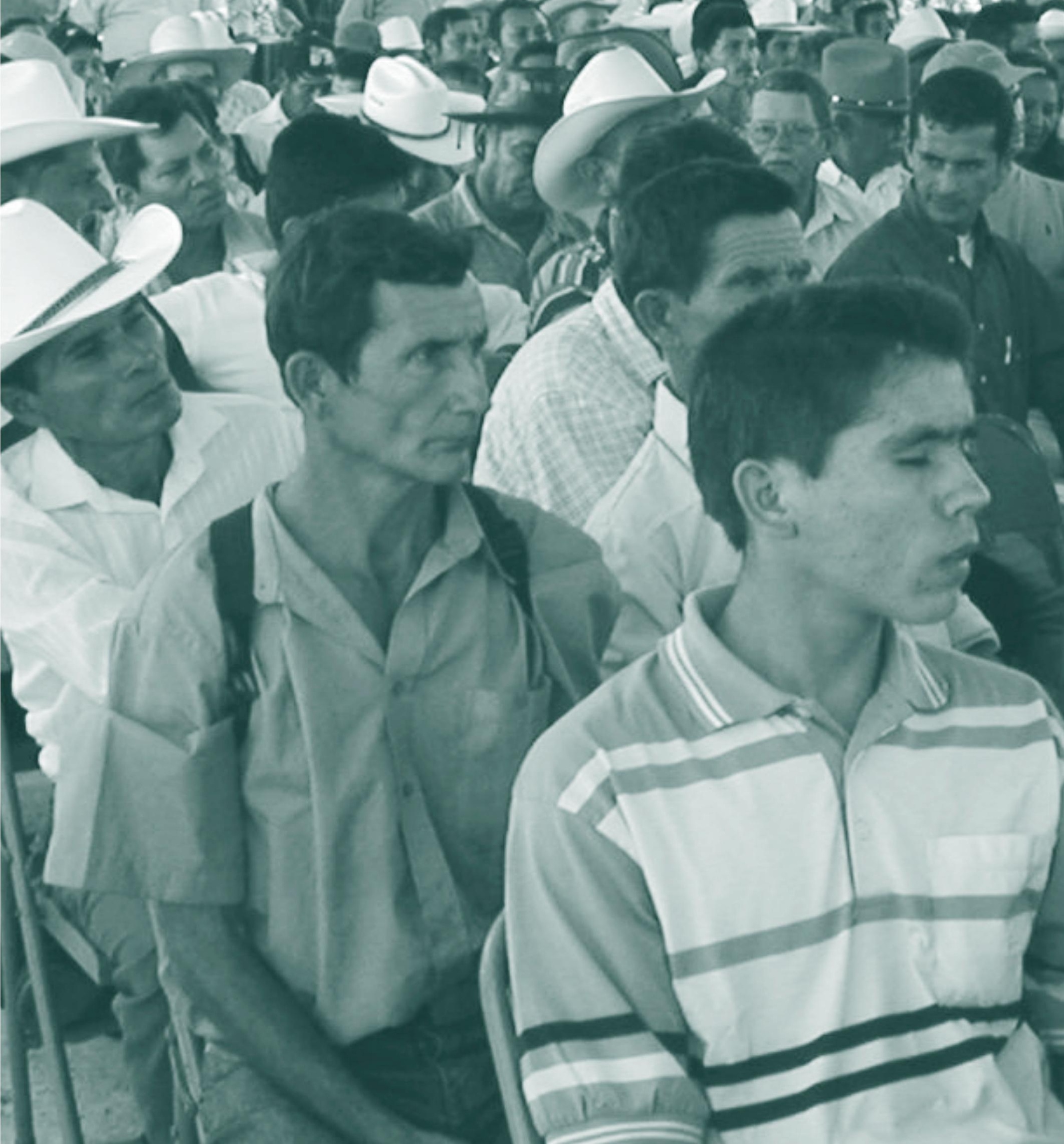




\section{6 relaciones norte-sur: cooperación internacional, población migrante y remesas}

Guillermo Molina Chocano ${ }^{5}$

Las relaciones $\mathrm{N}$ orte-Sur han sido definidas como el intercambio diferencial entre países desarrollados y los llamados "en vías de desarrollo" y abarca una serie de el ementos y aspectos crucial es con mayor complejidad a raíz de la profundización de la globalización económica, tecnológica, financiera y comunicacional. Un área crucial es el comercio internacional que representa una relación de intercambio desigual e inequitativa, debido al proteccionismo, los subsidios y las barreras no arancelarias impuestas por los países industrializados. Todo esto tiene lugar en el Ilamado "N U EV O SISTEM A INTER N A CIO N A L" representado por la época de la postguerra fría en donde surge un nuevo esquema mundial (orden / desorden) de carácter cada vez más multipolar, en donde los Estados Unidos se ve obligado a compartir decisiones con otras potencias como la Unión Europea, Japón, C hina, Rusia y otras naciones de rango medio regionales.

Esta multipolaridad se ha visto reflejada en el reciente conflicto de la guerra de invasión en contra de I rak en donde la mayoría de Iasnaciones del Consejo de Seguridad y de la A samblea de $\mathrm{N}$ aciones U nidas se opusieron a dicha intervención. Con su actitud Estados U nidos rompió la legalidad internacional y ahora se ve obligado a replantearse nuevos apoyos del Sistema de $\mathrm{N}$ aciones U nidas como el único canal y garantía de la paz mundial. O tro de los aspectos lo constituye la Cooperación Internacional que ha sido objeto de la cátedra de la M aestría en Demografía Social y G estión del DesarroIlo en donde se han analizado los grandes temas de la $A$ genda $M$ undial, tratados en las diferentes $C$ umbres patrocinadas por la $O \mathrm{NU}$, entre las que se destacan la de Población y Desarrollo (Cairo), M edio A mbiente, Seguridad A limentaria, Infancia, Racismo, M ujer, etc. que especifican las problemáticas y medi das al ternativas para su abordaje integral.

Por su parte, el tema de la cooperación internacional ha enfocado uno de los problemas más cruciales para el tercer mundo, como es el pago y readecuación de la deuda externa que constituye un problema de enorme magnitud y que desvía los recursos del desarroIlo hacia el pago de intereses y de amortización de capital, lo que trastorna total mentel as posibilidades de crecimien to económico con equidad social. Dentro de los enfoques de la cooperación internacional se destaca la importancia al reconocimiento y respeto de la multiculturalidad y el elemento clave del desarrollo local y el fortalecimiento municipal. También son tema de discusión el problema de la paz y la guerra, es decir los conflictos armados y el terrorismo, estimulado este último por posiciones integristas, fundamentalistas y de "pen samiento único" que rechazan la diversidad y no reconocen la importancia de las diferencias socio culturales y su derecho a la autodeterminación tanto en Palestina como en A frica e Hispanoamérica.

Desde el punto de vista de $\mathrm{C}$ entroamérica y $\mathrm{H}$ onduras en particular, resaltan Ios lineamientos establecidos en el Grupo de Estocolmo, con posterioridad a la negociación de la cooperación post$M$ itch en donde se establece la necesidad de la coordinación de las diferentes fuentes de cooperación internacional, dentro de un enfoque de esfuerzos asociados horizontal es con énfasis en la superación de la vulnerabilidad ecológica y social, la descentralización y la participación indispensable de la sociedad civil organizada, con funciones también de transparencia y auditoría social respecto a la ejecución de proyectos. En pocas palabras la cooperación internacional exige un enfoque más participativo de los distintos sectores de la sociedad civil y eficiencia, eficacia, equidad y sostenibilidad por parte de los diferentes programas y proyectos.

Desde otra perspectiva se han hecho serias críticas al fracaso del conjunto de políticas denominadas "consenso de W ashington", que asumiendo un enfoque neoliberal ponen el énfasis en el crecimiento económico por sí mismo y su respectivo "derrame" a los aspectos social es y ambiental es del desarrollo. A I respecto, el reciente Premio N óbel de Economía, J oseph Stiglitz, establece que no existe un único sistema "óptimo" ni una política "correcta" de abordar la problemática del crecimiento económico y el intercambio comercial, sino que las políticas de desarrollo deben definirse en función de un equilibrio y fortal ecimiento simultáneo tanto del Estado como del mercado para lograr una vinculación apropiada entre procesos políticos y económicos que lleven no solamente al alivio de la pobreza, sino a la tran sformación de toda la sociedad. Para ello propone la movilización social teniendo como elemento clave la asignación del gasto en educación, la salud, la alimentación y las redes de protección social. A simismo, una mayor equidad en la generación de empleo de calidad y justicia distributiva en las cargas fiscales y en último lugar un clima propicio para las empresas, para las políticas industriales, a los sistemas de ahorro y crédito que propicien la estabilidad macroeconómica.

A nivel de las relaciones $\mathrm{N}$ orte-Sur, J. Stiglitz señala la falta de 
equidad del sistema comercial mundial, en donde realmente los países desarrollados no abren sus mercados, ni reducen los subsidios y mucho menos las barreras no arancelarias. A ello se suma la inestabilidad del sistema financiero internacional, sacudido por crecientes turbulencias y fenómenos de especulación abierta. Como lo expresa G eorge Soros, éste parece ser el principal talón de aquiles del nuevo sistema internacional, donde dichas turbulencias financieras impiden un crecimiento sostenido y equitativo entre los países del norte y del sur. Se requerirían al respecto medidas mínimas de regulación para controlar los excesos de la especulación de los mercados de valores y bancarios, que incluso han afectado el corazón mismo de las metrópolis del capitalismo globalizado.

En el C urso de Políticas Internacionales de C ooperación para el Desarrollo de la M aestría en Demografía Social del PLATS de la U niversidad $\mathrm{N}$ acional A utónoma de $\mathrm{H}$ onduras se han analizado todas estas variables contextuales y en particular el caso específico de $\mathrm{H}$ onduras, donde la maquila, las remesas de los migrantes, los productos de exportación no tradicionales y el turismo representan en la actualidad las principales fuentes de financiamiento, inversión y empleo de la economía hondureña, más el aporte insustituible de la cooperación internacional que representa entre el $5 \%$ y el $10 \%$ del Producto Interno Bruto (PIB) y el $50 \%$ de la inversión pública en $\mathrm{H}$ onduras en lo que se refiere a infraestructura física, económica, social y ambiental, dentro de las diferentes modalidades de cooperación reembolsable y no reembolsable (bilateral y multilateral), tanto en el esquema de A yuda O ficial para el Desarrollo (A OD) como en los aportes directos de las O NG's y de los A yuntamientos que hermanan a corporaciones municipales del N orte y del Sur. Por su parte, las remesas familiares representan cerca del $11 \%$ del PIB, Io que nos aproxima a una cifra cercana a los mil millones de Dólares, superando así incluso la Inversión Extranjera Directa (IED)

En base al trabajo académico del mencionado $\mathrm{C}$ urso se presentan ahora tres estudios particulares elaborados por los estudiantes del mismo, con la respectiva asesoría Docente y en los que se analizan ejemplos concretos de la cooperación internacional en agua y saneamiento, educación básica y el rol de las remesas familiares que envían los migrantes hondureños, principalmente desde Estados U nidos, descubriendo sus montos, destinatarios y usos de las mismas, con el propósito de vislumbrar alternativas de ahorro y crédito e inversión en vivienda, microempresas y otros activos que ayuden a contribuir al desarrollo de las familias hondureñas, reduciendo los al tos costos de intermediación y de envío de tal es fon dos que puedan ser invertidos en la economía campesina o en el propio sector informal urbano, principales autogeneradores de empleo y de la canasta alimenticia básica de la población hondureña. 